\title{
Novel Potentiometric Sensor for Monitoring Beryllium Based on Naphto-9-crown-3
}

\author{
Mohammad Reza Ganjali, ${ }^{* \dagger}$ Azadeh Daftari, ${ }^{*}$ Majid FaAl-Rastegar, ${ }^{*}$ and \\ Abolghasem MoGHIMI** \\ *Departments of Chemistry, Tehran University, Tehran, Iran \\ **Departments of Chemistry, Imam Hossein University, Tehran, Iran
}

\begin{abstract}
A novel poly(vinyl chloride) (PVC) membrane electrode based on naphto-9-crown-3 was prepared and tested for the selective detection of beryllium ions. A suitable lipophilicity of the carrier and appropriate coordination ability were found to be essential for designing an electrode with good response characteristics. A PVC membrane with $9 \%$ naphtho9-crown-3 carrier, 58\% o-NPOE plasticizer, 3\% tetraphenylborate anionic excluder and 30\% poly(vinyl chloride) satisfied these requirements. The proposed sensor displayed a linear response to beryllium over a wide concentration range of $1.0 \times 10^{-1}-8.0 \times 10^{-6} \mathrm{M}$ with a Nernstian slope of $29.5 \mathrm{mV}$ per decade. The electrode showed very short response time $(<15 \mathrm{~s})$ and could be used in the $\mathrm{pH}$ range $3.5-9.0$. The selectivity coefficient for alkali, alkaline earth, transition and heavy metal ions was smaller than $4.0 \times 10^{-4}$. The sensor was successfully used as an indicator electrode in the potentiometric titration of $\mathrm{Be}^{2+}$ with EDTA. The proposed $\mathrm{Be}(\mathrm{II})$ sensor was also used for the determination of $\mathrm{Be}^{2+}$ ions in binary mixtures.
\end{abstract}

(Received June 25, 2002; Accepted October 25, 2002)

\section{Introduction}

A wide variety of chemically, clinically or environmentally important analytes are now routinely monitored using ionselective electrodes based on impregnated polymeric membranes. ${ }^{1}$ During the past two decades, an extensive effort has been expanded in the synthesis and characterization of neutral ionophores with high selectivities for specific metal ions and to develop new potentiometric and optical sensors for the determination of the respective metal ions in different real samples. ${ }^{2,3}$ Despite the urgent need for a beryllium sensor for the potentiometric determination of $\mathrm{Be}(\mathrm{II})$ in industrial and environmental samples, there have been only two reports of beryllium ion-selective electrodes in the literature. ${ }^{4,5}$ Recently, we used a neutral carrier in constructing PVC membrane electrodes for different metal ions, such as $\mathrm{K}, \mathrm{Sr}, \mathrm{Be}, \mathrm{Ni}, \mathrm{Cu}$, $\mathrm{Hg}, \mathrm{Cd}$ and $\mathrm{Ce}^{4-11}$ In this work, we report for the first time on the use of a new crown ether (naphto-9-crown-3, NCE) which was recently synthesized in our laboratory ${ }^{12}$ as an excellent neutral carrier with good lipophilicity in the construction of a beryllium-selective PVC membrane sensor for the selective monitoring of $\mathrm{Be}(\mathrm{II})$ in various samples.

\section{Experimental}

\section{Reagents}

Reagent-grade acetophenone (AP), nitrobenzene (NB), onitrophenyloctyl ether (NPOE), sodium tetraphenylborate

† To whom correspondence should be addressed.

E-mail: Ganjali@khayam.ut.ac.ir
(NaTPB), high relative molecular weight $\mathrm{PVC}$, oleic acid (OA) and tetrahydrofurane (THF) were purchased from Merck Chemical and used as received. The ionophore NCE (Fig. 1) was synthesized and purified by our laboratory, as described elsewhere. ${ }^{12}$ Reagent-grade nitrate and chloride salts of the cations used (all from Merck) were of the highest purity available and used without any further purification, except for vacuum drying over $\mathrm{P}_{2} \mathrm{O}_{5}$. Triply distilled deionized water was used throughout.

\section{Electrode preparation}

The membrane solution was prepared by dissolving $9 \mathrm{mg}$ of $\mathrm{NCE}, 30 \mathrm{mg}$ of PVC, $3 \mathrm{mg}$ of NaTPB and $58 \mathrm{mg}$ of NPOE in 5 $\mathrm{ml}$ of THF. The resulting mixture was transferred into a glass dish of $2 \mathrm{~cm}$ diameter. The solvent was evaporated slowly, until an oily concentrated mixture was obtained. A Pyrex tube (3- $5 \mathrm{~mm}$ diameter on top) was dipped into the oily mixture for about $10 \mathrm{~s}$ so that a non-transparent film of about $0.3 \mathrm{~mm}$ thickness was formed. ${ }^{4-11}$ The tube was then pulled out from the mixture and kept at room temperature for about $1 \mathrm{~h}$. The tube was then filled with an internal filling solution $\left(1.0 \times 10^{-3} \mathrm{M}\right.$ $\mathrm{BeCl}_{2}$ ). The electrode was finally conditioned for $24 \mathrm{~h}$ by soaking in a $1.0 \times 10^{-2} \mathrm{M}$ solution of beryllium chloride. A silver-silver chloride electrode was used as an internal reference electrode. The ratio of different membrane ingredients,

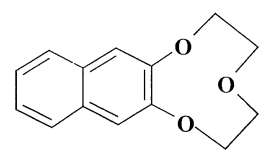

Fig. 1 Structure of the NCE. 


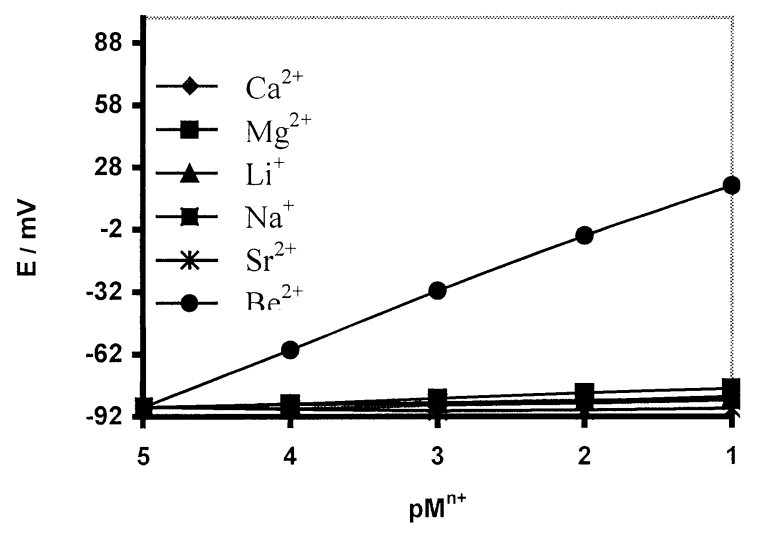

Fig. 2 Potential response of various ion-selective electrodes based on NCE.

Table 1 Composition of membrane ingredients

\begin{tabular}{|c|c|c|c|c|c|}
\hline \multirow{2}{*}{ No. } & \multicolumn{4}{|c|}{$\%$ Composition } & \multirow{2}{*}{ 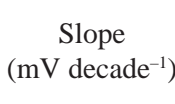 } \\
\hline & PVC & NCE & Plasticizer & Additive & \\
\hline 1 & 30 & 3 & $67, \mathrm{AP}$ & - & 8.0 \\
\hline 2 & 30 & 6 & 64, AP & - & 10.2 \\
\hline 3 & 30 & 9 & $61, \mathrm{AP}$ & - & 14.0 \\
\hline 4 & 30 & 10 & $60, \mathrm{AP}$ & - & 13.0 \\
\hline 5 & 30 & 9 & $58, \mathrm{AP}$ & 3, ТPB & 18.3 \\
\hline 6 & 30 & 9 & $58, \mathrm{NB}$ & 3, ТРВ & 23.5 \\
\hline 7 & 30 & 9 & $58, \mathrm{NPOE}$ & 3, ТРВ & 29.5 \\
\hline
\end{tabular}

concentration of equilibrating solution and the time of contact were optimized to provide membranes, which result in reproducible, noiseless and stable potentials.

\section{Emf measurements}

All emf measurements were carried out with the following assembly:

$\mathrm{Ag}-\mathrm{AgCl} / \mathrm{PVC}$ membrane (internal solution $1.0 \times 10^{-3} \mathrm{M}$ $\mathrm{BeCl}_{2}$ )/test solution/ $\mathrm{Hg}-\mathrm{Hg}_{2} \mathrm{Cl}_{2}, \mathrm{KCI}$ (satd.).

A Corning ion analyzer $250 \mathrm{pH} / \mathrm{mV}$ meter was used for potential measurements at $25.0 \pm 0.1^{\circ} \mathrm{C}$. The emf observations were made relative to a double-junction saturated calomel electrode (SCE, Philips) with the outer chamber filled with an ammonium nitrate solution.

The activities were calculated according to the Debye-Hückle procedure. $^{14}$

\section{Results and Discussion}

Due to its sufficient insolubility in water, rigid structure and, especially, the presence of three donating oxygen atoms in its structure, NCE was expected to act as a suitable ion carrier in PVC membranes with respect to special alkali and alkaline earth metal ions of proper size and charge. Thus, it was at first used as a neutral carrier to prepare PVC-based membrane electrodes for $\mathrm{Li}, \mathrm{Na}, \mathrm{K}, \mathrm{Be}, \mathrm{Mg}, \mathrm{Ca}$ and $\mathrm{Sr}$ ions. The potential responses of these ion-selective membrane sensors are illustrated in Fig. 2. As can be seen, among different cations used, $\mathrm{Be}^{2+}$ with the most sensitive response seems to be suitably determined with the PVC membrane based on NCE. This is probably due to the selective behavior of the ionophore against $\mathrm{Be}^{2+}$ compared to

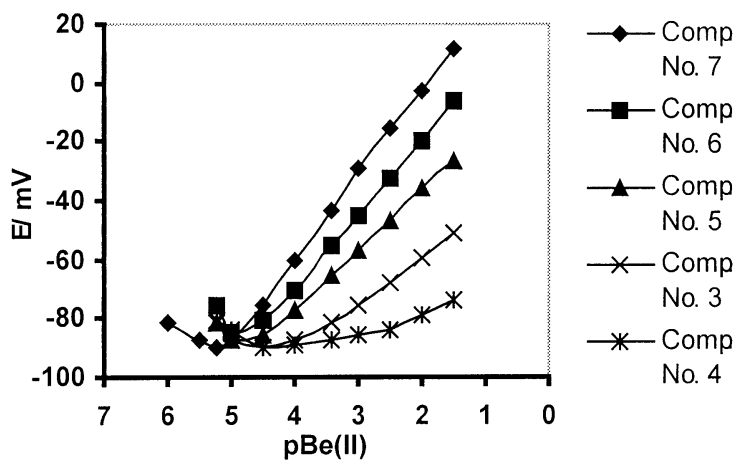

Fig. 3 Calibration curves for Be(II) sensors based on NCE with different compositions.

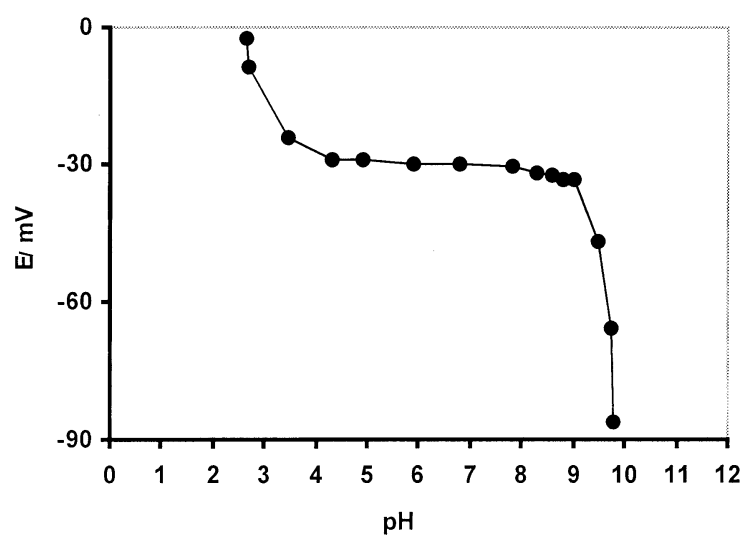

Fig. 4 Effect of the $\mathrm{pH}$ of the test solution $\left(1.0 \times 10^{-3} \mathrm{M}\right)$ on the potential response of the $\mathrm{Be}^{2+}$ ion-selective electrode.

other metal ions. The same behavior has already been seen. ${ }^{8}$

\section{Optimization of membrane composition}

The sensitivity and selectivity of ion-selective electrodes are known to be dependent not only on the nature of the ionophore, but also significantly on the composition of the membrane ingredients. ${ }^{411,14,15}$ Thus, the effects of the membrane composition, the nature and amount of plasticizer and sodium tetraphenyl borate (NaTPB) as a lipophilic additive on the potential response of the $\mathrm{Be}^{2+}$ sensor were investigated. The results are given in Table 1. As can be seen, between the two different plasticizers used, NPOE resulted in the best sensitivity. Moreover, 9\% of NCE was chosen as the optimum amount of ionophore in the PVC membrane (No. 7).

The data given in Table 1 reveal that in the absence of any additive, the sensitivity of the sensor is quite low (No. 3 with a slope of $14.0 \mathrm{mV}$ per decade). However, the presence of $3 \%$ NaTPB improves the sensitivity of the $\mathrm{Be}^{2+}$ sensor considerably (No. 7 with a slope of $29.5 \mathrm{mV}$ per decade).

The time of contact and concentration of the equilibrating solution were optimized so that the sensor generated stable and reproducible potentials at relatively short response times. The optimum equilibration time in a $1 \times 10^{-3} \mathrm{M} \mathrm{BeCl}_{2}$ solution was $24 \mathrm{~h}$. The critical response characteristics of the beryllium sensor were assessed according to IUPAC recommendations. ${ }^{16}$ The potential response of the sensor at varying concentrations of beryllium ion (Fig. 3, calibration graph) shows a linear range from $1.0 \times 10^{-1}$ to $8.0 \times 10^{-6} \mathrm{M}$ with a slope of $29.5 \pm 0.4 \mathrm{mV}$ per decade. The detection limit, as determined from the 
Table 2 Selectivity coefficients of various interfering ions

\begin{tabular}{lccccc}
\hline & \multicolumn{5}{c}{ Electrode } \\
\cline { 2 - 6 } Ion & 3 & 4 & 5 & 6 & 7 \\
\hline $\mathrm{Li}^{+}$ & $5.1 \times 10^{-3}$ & $5.4 \times 10^{-3}$ & $3.1 \times 10^{-3}$ & $1.6 \times 10^{-3}$ & $2.7 \times 10^{-4}$ \\
$\mathrm{Ca}^{2+}$ & $3.9 \times 10^{-3}$ & $4.0 \times 10^{-3}$ & $2.5 \times 10^{-3}$ & $1.5 \times 10^{-3}$ & $2.1 \times 10^{-4}$ \\
$\mathrm{Mg}^{2+}$ & $7.2 \times 10^{-3}$ & $7.9 \times 10^{-3}$ & $4.1 \times 10^{-3}$ & $2.4 \times 10^{-3}$ & $3.8 \times 10^{-4}$ \\
$\mathrm{Na}^{+}$ & $4.5 \times 10^{-3}$ & $4.3 \times 10^{-3}$ & $2.3 \times 10^{-3}$ & $1.2 \times 10^{-3}$ & $2.2 \times 10^{-4}$ \\
$\mathrm{Sr}^{2+}$ & $2.3 \times 10^{-3}$ & $2.5 \times 10^{-3}$ & $1.1 \times 10^{-3}$ & $6.7 \times 10^{-4}$ & $1.1 \times 10^{-4}$ \\
$\mathrm{~K}^{+}$ & $2.7 \times 10^{-3}$ & $2.9 \times 10^{-3}$ & $1.6 \times 10^{-3}$ & $8.1 \times 10^{-4}$ & $1.4 \times 10^{-4}$ \\
$\mathrm{Ba}^{2+}$ & $3.5 \times 10^{-3}$ & $3.8 \times 10^{-3}$ & $2.1 \times 10^{-3}$ & $1.3 \times 10^{-3}$ & $1.9 \times 10^{-4}$ \\
\hline
\end{tabular}

Conditions: reference solution $\left(1.0 \times 10^{-6} \mathrm{M}\right.$ of $\left.\mathrm{Be}^{2+}\right)$, primary ion $\left(1.0 \times 10^{-6}-1.0 \times 10^{-3} \mathrm{M}\right.$ of $\left.\mathrm{Be}^{2+}\right)$, interfering ion $\left(1.0 \times 10^{-3}-1.0 \times\right.$ $\left.10^{-2} \mathrm{M}\right)$.

Table 3 Comparison of the selectivity coefficient, detection limit and response time of various $\mathrm{Be}(\mathrm{II})$ ion-selective electrodes

\begin{tabular}{lcccc}
\hline & $\begin{array}{c}\text { Ref. 4 } \\
(\mathrm{MSM})\end{array}$ & $\begin{array}{c}\text { Ref. 5 } \\
(\mathrm{MSM})\end{array}$ & $\begin{array}{c}\text { This work } \\
(\mathrm{MPM})\end{array}$ & $\begin{array}{c}\text { This work } \\
(\mathrm{MSM})\end{array}$ \\
\hline $\begin{array}{l}\text { Detection } \\
\text { limit, ppm }\end{array}$ & $1.0 \times 10^{-6}$ & $8.0 \times 10^{-7}$ & $6 \times 10^{-6}$ & $6 \times 10^{-6}$ \\
$\begin{array}{l}\text { Response } \\
\text { time/s }\end{array}$ & 50 & & & \\
& & 30 & 15 & 15 \\
$\mathrm{Li}^{+}$ & $5.1 \times 10^{-3}$ & $9.1 \times 10^{-3}$ & $2.7 \times 10^{-4}$ & $4.5 \times 10^{-3}$ \\
$\mathrm{Na}^{+}$ & $3.8 \times 10^{-3}$ & $8.3 \times 10^{-3}$ & $2.2 \times 10^{-4}$ & $3.6 \times 10^{-3}$ \\
$\mathrm{~K}^{+}$ & $2.7 \times 10^{-4}$ & $7.8 \times 10^{-3}$ & $1.7 \times 10^{-4}$ & $8.5 \times 10^{-4}$ \\
$\mathrm{Mg}^{2+}$ & $2.0 \times 10^{-3}$ & $2.8 \times 10^{-3}$ & $3.8 \times 10^{-4}$ & $7.7 \times 10^{-4}$ \\
$\mathrm{Ca}^{2+}$ & $1.6 \times 10^{-4}$ & $7.2 \times 10^{-4}$ & $2.1 \times 10^{-4}$ & $4.4 \times 10^{-4}$ \\
$\mathrm{Sr}^{2+}$ & $1.4 \times 10^{-4}$ & $8.2 \times 10^{-4}$ & $1.1 \times 10^{-4}$ & $2.3 \times 10^{-4}$ \\
$\mathrm{Ba}^{2+}$ & $1.2 \times 10^{-4}$ & $8.0 \times 10^{-4}$ & $1.9 \times 10^{-4}$ & $2.8 \times 10^{-4}$ \\
\end{tabular}

Ref. 4: Benzo-9-crown-3. Ref. 5: 3,4-Di[2-(2-tetraphydro-2Hpyranoxy)]-ethoxy styrene copolymer.

intersection of the two extrapolated segments of the calibration plots, was $6.0 \times 10^{-6} \mathrm{M}$.

The $\mathrm{pH}$ response profile for the sensor was tested using $1.0 \times$ $10^{-3} \mathrm{M}$ of $\mathrm{BeCl}_{2}$ solutions over the $\mathrm{pH}$ range $2.5-10.0$. The $\mathrm{pH}$ was adjusted by using small drops of hydrochloric acid or sodium hydroxide. The effect of the $\mathrm{pH}$ response on the PVC membrane electrode is shown in Fig. 4. As can be seen, the potential stayed constant from pH 3.5 to 9.0 , beyond which a drift in the potential was observed. The observed drift at higher $\mathrm{pH}$ values could be due to the formation of beryllium hydroxide in the solution. At lower $\mathrm{pH}$, the potential increased, indicating that the membrane sensor responded to hydrogen ions.

The effect of interfering ions on the response behavior of the sensors is described in terms of the selectivity coefficients, $\left(K_{\text {sel }}\right)$. Methods based on the Nicolsky-Eisenman equation for the determination of potentiometric selectivity coefficients (e.g. the fixed interference method and the mixed solution method) are among the most commonly methods used thus far. ${ }^{17,18}$ However, it has been shown that these methods suffer some limitations in terms of the values for ions of unequal charges, a non-Nernstian behavior of interfering ions, and the activity dependence of the values. ${ }^{19,20}$ Thus, in this work, the recommended matched potential method (MPM), which is totally independent of the Nicolsky-Eisenman equation, was used to overcome the above-stated difficulties. ${ }^{21}$ According to the MPM, a specified activity (concentration) of primary ions (A) was added to a reference solution and the potential was

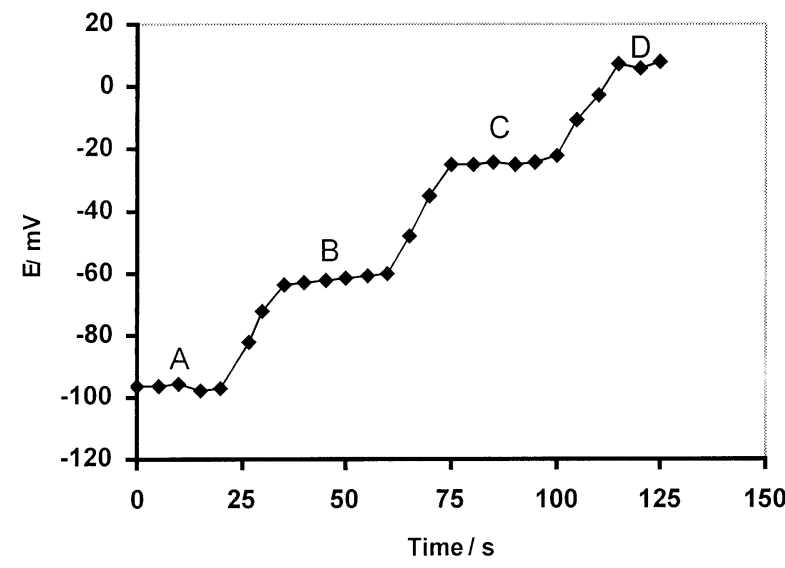

Fig. 5 Dynamic response of the NCE membrane electrode for step changes in the concentration of $\mathrm{Be}^{2+}$; A) $1.0 \times 10^{-5} \mathrm{M}$, B) $1.0 \times 10^{-4}$ $\mathrm{M}$, C) $1.0 \times 10^{-3} \mathrm{M}$, D) $1.0 \times 10^{-2} \mathrm{M}$.

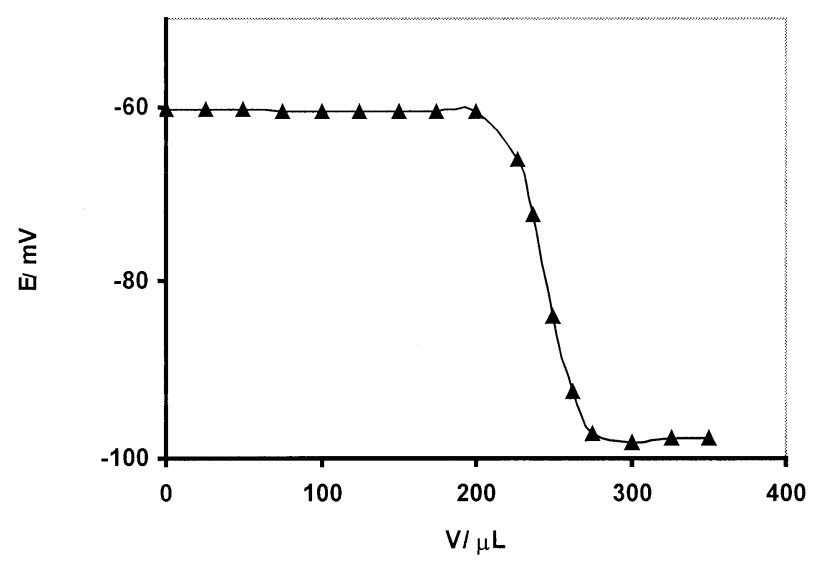

Fig. 6 Potentiometric titration curve of $25.0 \mathrm{ml}$ of $1.0 \times 10^{-4} \mathrm{M}$ $\mathrm{Be}^{2+}$ with $1.0 \times 10^{-2} \mathrm{M}$ EDTA, using the proposed membrane sensor as an indicator electrode.

measured. In a separate experiment, interfering ions (B) were successively added to an identical reference solution, until the measured potential matched the one obtained before by adding primary ions. The MPM selectivity coefficient, $\left(K_{\text {sel }}\right)$ was then given by the resulting primary ion to the interfering ion activity (concentration) ratio, $K_{\mathrm{sel}}=a_{\mathrm{A}} / a_{\mathrm{B}}$. The experimental conditions employed and the resulting values for different $\mathrm{Be}(\mathrm{II})$ ion sensors are given in Table 2. As can be seen, for all of the diverse ions used, the selectivity coefficients in the case of the best composition (No. 7) were in the order of $4.0 \times 10^{-4}$ or smaller, indicating that they would not significantly disturb the functioning of the $\mathrm{Be}^{2+}$ ion-selective electrode. The super selectivity of the proposed sensor, most probably due to its small ionic size and much higher charge density, was compared with other cations.

Table 3 compares the response time, detection limit and selectivity coefficients of the proposed sensor with both of the beryllium-selective electrodes reported in the literature. ${ }^{4,5}$ The results clearly indicate the superiority of the proposed electrode in terms of the response time and the selectivity coefficients (for $\mathrm{Mg}^{2+}, \mathrm{Na}^{+}$and $\mathrm{Li}^{+}$ions).

The dynamic response time is an important factor for any ionselective electrode. In this study, the practical response time was recorded by changing the $\mathrm{Be}^{2+}$ concentration in solution, 
Table 4 Recovery of beryllium ions from binary mixtures

\begin{tabular}{ccrc}
\hline $\mathrm{Be}^{+2} / \mu \mathrm{g} \mathrm{mL}^{-1}$ & $\begin{array}{c}\text { Added cations/ } \\
\mu \mathrm{g} \mathrm{mL}^{-1}\end{array}$ & $\begin{array}{c}\text { Recovery \% } \\
\text { of } \mathrm{Be}^{+2}\end{array}$ & $\begin{array}{c}\text { Recovery \% of } \\
\mathrm{Be}^{+2} \text { by AAS }\end{array}$ \\
\hline 5.0 & - & $98.9 \pm 0.3$ & $99.7 \pm 0.2$ \\
5.0 & $50 \mathrm{Na}^{+}$ & $99.7 \pm 0.3$ & $99.5 \pm 0.4$ \\
5.0 & $500 \mathrm{Na}^{+}$ & $99.5 \pm 0.3$ & $100.1 \pm 0.2$ \\
5.0 & $500 \mathrm{~K}^{+}$ & $99.4 \pm 0.6$ & $100.0 \pm 0.3$ \\
5.0 & $500 \mathrm{Mg}^{2+}$ & $100.2 \pm 0.5$ & $99.9 \pm 0.2$ \\
5.0 & $500 \mathrm{Fe}^{3+}$ & $100.1 \pm 0.6$ & $99.7 \pm 0.3$ \\
5.0 & $500 \mathrm{Cu}^{2+}$ & $99.3 \pm 0.7$ & $99.6 \pm 0.2$ \\
5.0 & $500 \mathrm{~Pb}^{2+}$ & $98.8 \pm 0.3$ & $99.7 \pm 0.5$ \\
5.0 & $500 \mathrm{Ca}^{2+}$ & $99.1 \pm 0.7$ & $99.5 \pm 0.3$ \\
5.0 & $500 \mathrm{Zn}^{2+}$ & $99.3 \pm 0.5$ & $99.8 \pm 0.2$ \\
\hline
\end{tabular}

over a concentration range of $1.0 \times 10^{-1}-1.0 \times 10^{-5} \mathrm{M}$. The actual potential versus time traces is shown in Fig. 5. As can be seen, over the whole concentration range the electrode reaches its equilibrium response in a very short time $(<15 \mathrm{~s})$.

The proposed beryllium membrane electrode was found to work well under laboratory conditions. It was successfully applied to the titration of a $20.0 \mathrm{ml}$ of $1.0 \times 10^{-4} \mathrm{M} \mathrm{Be}^{2+}$ solution with $1.0 \times 10^{-2} \mathrm{M}$ EDTA. The resulting titration curve is shown in Fig. 6. As can be seen, the amount of $\mathrm{Be}^{2+}(1.1 \pm 0.1) \times 10^{-4}$ $\mathrm{M}$ in the solution can be accurately determined with the electrode.

The applicability of the sensor was illustrated by measuring beryllium ion in water samples spiked with 10, 20 and $30 \mathrm{ppm}$ beryllium ion by direct potentiometry. The obtained results were compared with those obtained by an atomic absorption spectrometric (AAS) analysis (Table 4) and potentiometry, and were found to be in good agreement.

\section{References}

1. M. E. Meyerhoff and M. N. Opdychc, Adv. Clin. Chem., 1986, $25,1$.

2. D. Ammann, W. E. Moody, P. C. Meier, E. Pretsch, and W. Simon, Ion. Sel. Electrode Rev., 1983, 5, 3.
3. P. Bühlmann, E. Pretsch, and E. Bakker, Chem. Rev., 1998, 98, 5593.

4. M. R. Ganjali, M. Shamsipur, and A. Moghimi, Anal. Chem., 1998, 70, 5259.

5. M. Shamsipur, M. R. Ganjali, A. Rouhollahi, and A. Moghimi, Anal. Chim. Acta, 2001, 434, 23.

6. M. R. Ganjali, T. Poursaberi, L. H. A. Babaei, S. Rouhani, M. Y. Yousefi, M. Kargar-Razi, A. Moghimi, H. Aghabozorg, and M. Shamsipur, Anal. Chim. Acta, 2001, $440,81$.

7. M. Shamsipur, M. Yousefi, and M. R. Ganjali, Anal. Chem., 2000, 72, 2391.

8. M. R. Ganjali, M. R. Fathi, H. Rahmani, and H. Pirelahi, Electroanalysis, 2000, 12, 1138.

9. M. Shamsipur, S. Rouhani, H. Sharghi, M. R. Ganjali, and H. Eshghi, Anal. Chem., 1999, 71, 4938.

10. M. Shamsipur, T. Poursaberi, S. Rouhani, K. Nikname, H. Sharghi, and M. R. Ganjali, Anal. Sci., 2001, 17, 1049.

11. M. Javanbakht, A. Shabani-Kia, M. R. Darvich, M. R. Ganjali, and M. Shamsipur, Anal. Chim. Acta, 2000, 408, 75.

12. M. Shamsipur, M. Yousefi, M. Hosseini, and M. R. Ganjali, Anal. Lett., 2001, 34, 2249.

13. A. Moghimi, M. F. Rastegar, M. Ghandi, G. W. Buchanan, and H. Rahbarnoohi, J. Mol. Struc., 2000, 526, 185.

14. S. Kamata, A. Bhale, Y. Fukunaga, and A. Murata, Anal. Chem., 1998, 60, 2464.

15. E. Bakker, P. Bühlmann, and E. Pretsch, Chem. Rev., 1997, 97, 3083.

16. M. Huser, P. M. Gehring, W. E. Morf, W. Simon, E. Linder, J. Jeney, K. Toth, and E. Pungor, Anal. Chem., 1991, 63, 1330.

17. IUPAC Analytical Chemistry Division. Commission on Analytical Nomenclature, Pure Appl. Chem., 1976, 48, 127.

18. A. R. Fakhari, M. R. Ganjali, and M. Shamsipur, Anal. Chem., 1997, 69, 3693.

19. T. Ogata, I. D. A. Chowdhury, S. Kamata, Y. S. Usui, and K. Ohashi, Chem. Lett., 1995, 1041.

20. Y. Umezawa, K. Umezawa, and H. Sato, Pure Appl. Chem., 1995, 67, 507.

21. E. Bakker, Electroanalysis, 1997, 9, 7.

22. E. Bakker, Anal. Chem., 1997, 69, 1061. 